American Journal of Applied Sciences 4 (5): 307-316, 2007

ISSN 1546-9239

(C) 2007 Science Publications

\title{
Using PLC for Custom-design of a PID/PWM Program to Control a Heater Temperature
}

\author{
Mohammad A.K.Alia \\ Faculty of Engineering Technology, Al - Balqa' Applied University, Jordan
}

\begin{abstract}
This is a practical approach to control a continuous-time process variable (temperature) using a discrete controller (PLC) and a custom-designed software control algorithm and hardware interface, in a closed-loop system. Unlike the conventionally known technique of transforming a digital control action into a proportional analogue one by a D/A converter followed by power amplifier, the control action was formed internally by the PLC as a PID/PWM signal, which was used to trigger the power stage. This approach helped reducing the error due $\mathrm{D} / \mathrm{A}$ conversion, maximized utilization of the PLC and reduced total cost. The control system is realized by utilizing the heater of the training board (RGT1), manufactured by DL-lorenzo Company and it simulates an analogue heating control system. The PLC is Siemens Simatic S7-214 model. An experimental result has shown that the control algorithm functions perfectly.
\end{abstract}

Key words: PLC, PID software program, PWM, PLC, analogue input digital output, interface board

\section{INTRODUCTION}

The use of a digital signal processor (DSP) to evaluate the actual value of an analogue process output and then compute a correction signal has many advantages. DSP does not suffer from the long-term drift effect that analogue circuits do. Changes to constants can easily be made without the actual physical change to the circuitry and simply modifying the loaded program or loading a new one can radically alter the mode of control. Realizing PWM techniques and other advanced functions is some of the vast power points of digital controllers. Actually, in most cases DSPs are designed to replace the ON-line analogue ones. This explains the continuous approaches to implement digitally the traditional analogue control modes such as PID actions.

Because of the advantages of the PLCs ${ }^{[1]}$, a PLC type S7-200 was utilized as a DSP. Nowadays most modern sequential control systems are based on PLCs, which are in fact specialized industrial computers. Thus, one of the targets of this work is to design a PLC program for PID control algorithm and to develop it to get at the PLC output a PWM signal proportional to the value at the output of PID controller. In this case there is no need for a DAC IC nor for a specific power amplifier stage. Here the PWM signal with the power static switch emulates the function of a D-type power amplifier. From another side, by using the designed interface board, one can exclude the implementation of a high cost proprietary power interface module, this simplifies the circuit and reduces its cost.

PLC manufacturers very often provide the option of analogue I/O and support instant PID functions for extra cost. Such functions can be used directly by entering the control parameters and constants. Nevertheless, this feature is only usable if the analogue I/O module is installed. Therefore PID algorithm was designed instead of using a ready one. This, also, provides more flexibility to use the program with those PLCs, which do not support ready PID loops. Designed I/O board shown in Fig. 1 satisfies our demands and costs one third of the I/O module's cost approximately.

Because of the limited size of this paper, the design procedure of the $\mathrm{I} / \mathrm{O}$ interface board is not illustrated. It will be published in a special paper. However, I would like to add that cost is not the only factor. As Johnson ${ }^{[2]}$ wrote: (every engineer has personal preferences as to which flavor of PID algorithm should be used in any particular situation). For example full PID algorithm can only be used when the signal has little noise or where suitable filtering or limiting has been applied. Another example is that the derivative action could be on the process variable only and could be on the system error depending on the severity of change of system error. In our study we make use of the digital values of the PID output to initiate a PWM signal in order to control the timing of the power switch.

PLC application consideration: The SIMATIC S7200 with CPU-214 supports many of the familiar 


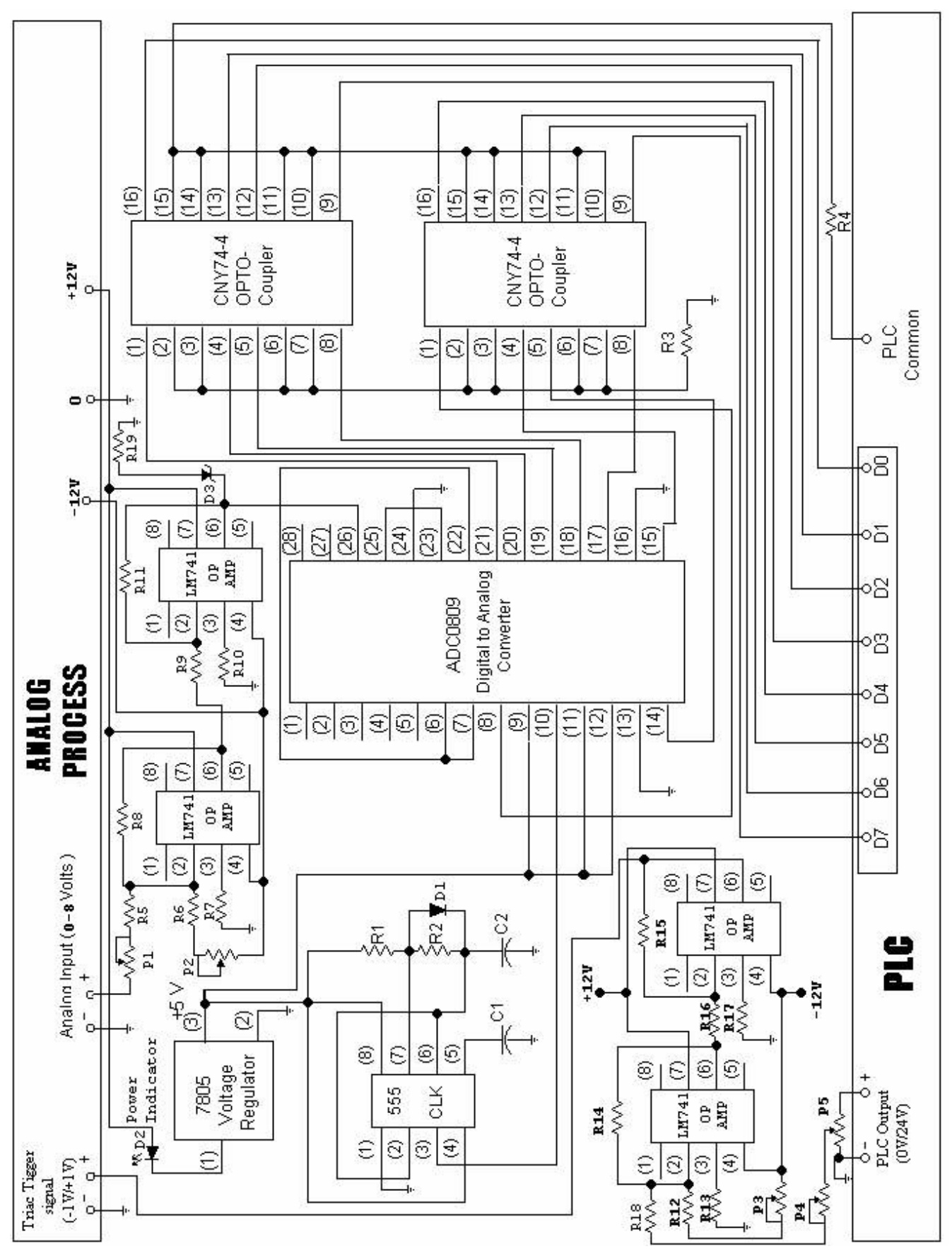

\begin{tabular}{llllllllll}
\hline $\mathrm{R} 1$ & $750 \Omega$ & $\mathrm{R} 7$ & $1.2 \mathrm{~K} \Omega$ & $\mathrm{R} 13$ & $39 \mathrm{~K} \Omega$ & $\mathrm{R} 19$ & $75 \Omega$ & $\mathrm{C} 1$ & $0.1 \mu \mathrm{F}$ \\
$\mathrm{R} 2$ & $750 \Omega$ & $\mathrm{R} 8$ & $100 \mathrm{~K} \Omega$ & $\mathrm{R} 14$ & $47 \mathrm{~K} \Omega$ & $\mathrm{P} 1$ & $100 \mathrm{~K} \Omega$ & $\mathrm{C} 2$ & $100 \mu \mathrm{F}$ \\
$\mathrm{R} 3$ & $75 \Omega$ & $\mathrm{R} 9$ & $2.2 \mathrm{~K} \Omega$ & $\mathrm{R} 15$ & $2.2 \mathrm{~K} \Omega$ & $\mathrm{P} 2$ & $500 \mathrm{~K} \Omega$ & $\mathrm{D} 1$ & $\mathrm{~S} i l i c o n$ \\
$\mathrm{R} 4$ & $15 \Omega$ & $\mathrm{R} 10$ & $1.2 \mathrm{~K} \Omega$ & $\mathrm{R} 16$ & $2.2 \mathrm{~K} \Omega$ & $\mathrm{P} 3$ & $1 \mathrm{M} \Omega$ & $\mathrm{D} 2$ & $2.2 \mathrm{LED}$ \\
$\mathrm{R} 5$ & $120 \mathrm{~K} \Omega$ & $\mathrm{R} 11$ & $2.2 \mathrm{~K} \Omega$ & $\mathrm{R} 17$ & $1.2 \mathrm{~K} \Omega$ & $\mathrm{P} 4$ & $300 \mathrm{~K} \Omega$ & $\mathrm{D} 3$ & $\mathrm{Zener} 5 \mathrm{~V}$ \\
$\mathrm{R} 6$ & $325 \mathrm{~K} \Omega$ & $\mathrm{R} 12$ & $325 \mathrm{~K} \Omega$ & $\mathrm{R} 18$ & $150 \mathrm{~K} \Omega$ & $\mathrm{P} 5$ & $2.4 \mathrm{~K} \Omega$ & -- & -- \\
\hline
\end{tabular}

Fig. 1: ADIC schematic 
Am. J. Applied Sci., 4 (5): 307-316, 2007

Table 1: Eight parallel lines connected to eight input points of the PLC convey the instantaneous temperature value

\begin{tabular}{lcc}
\hline Input number & $\rightarrow$ & Input point \\
\hline 0 & $\rightarrow$ & I 1.0 \\
1 & $\rightarrow$ & I 0.1 \\
2 & $\rightarrow$ & I 0.2 \\
3 & $\rightarrow$ & I 0.3 \\
4 & $\rightarrow$ & I 0.4 \\
5 & $\rightarrow$ & I 0.5 \\
6 & $\rightarrow$ & I 0.6 \\
7 & & I 0.7 \\
\hline
\end{tabular}

Table 2: PLC program written in ladder diagram and statement list forms and illustrated network by network

\begin{tabular}{l}
\hline \\
- $\quad$ On first scan, set image register bit "High". \\
- Call SUBROUTINE 0. \\
- First scan is indicated by the special memory bit SM0.1 \\
Network 2
\end{tabular}

Network 2

Network 1
STL
LD SMO.1
$S$ S $0.0,1$
CALL 0

- Call SUBROUTINE 0

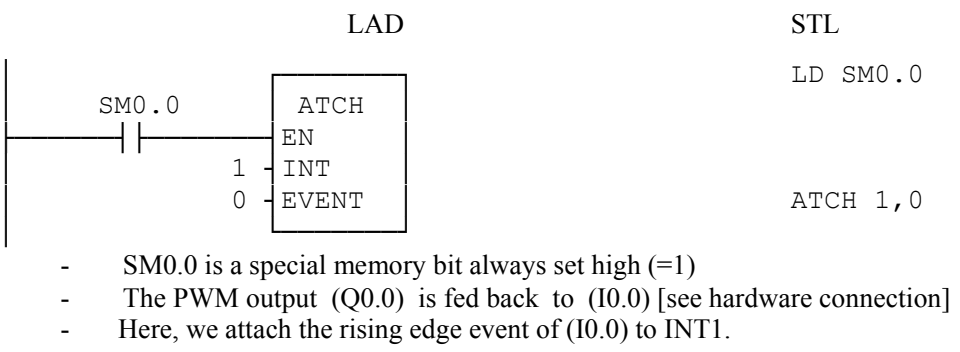

Network 3

The PWM output (Q0.0) is fed back to (I0.0) [see hardware connection]



- $\quad$ Transfer the status of all inputs (I0.0,I0.1 ... I0.7) as a Byte called (VB0) containing the process variable value .

- Note: this action involves (I0.0), which is not technically a process variable bit, for instance, this will not cause errors and shall be treated soon. Network 4
\begin{tabular}{rl}
$\mathrm{I} 1.0$ & $\mathrm{~V} 0.0$ \\
\hline &
\end{tabular}
LAD
STL
LD I1.0
$=\mathrm{V} 0.0$ Network 5

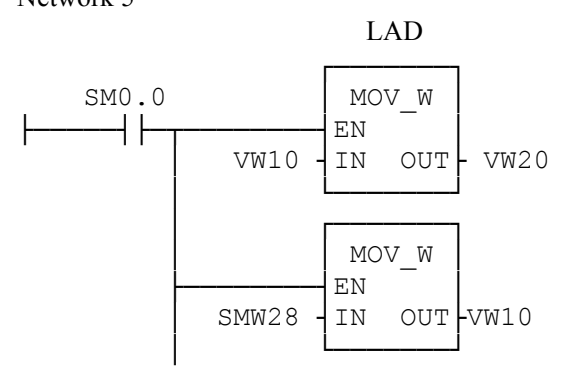

STL

LD SMO.0

MOVW VW10, VW20

MOVW SMW28, VW10 
Am. J. Applied Sci., 4 (5): 307-316, 2007

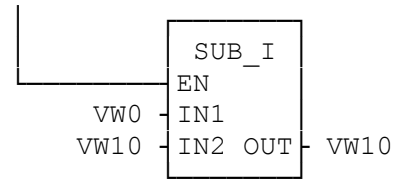

- I VW0, VW10

Each program cycle:

- $\quad$ Store previous error in (VW20).

- $\quad$ Store the set point value in (VW10), this value is generated using analog adjustment feature of CPU-214.

- $\quad$ Subtract the process variable PV (VW0) from the set point Sp (VW10) and get the result representing ERROR stored in (VW10).

Network 6




Am. J. Applied Sci., 4 (5): 307-316, 2007

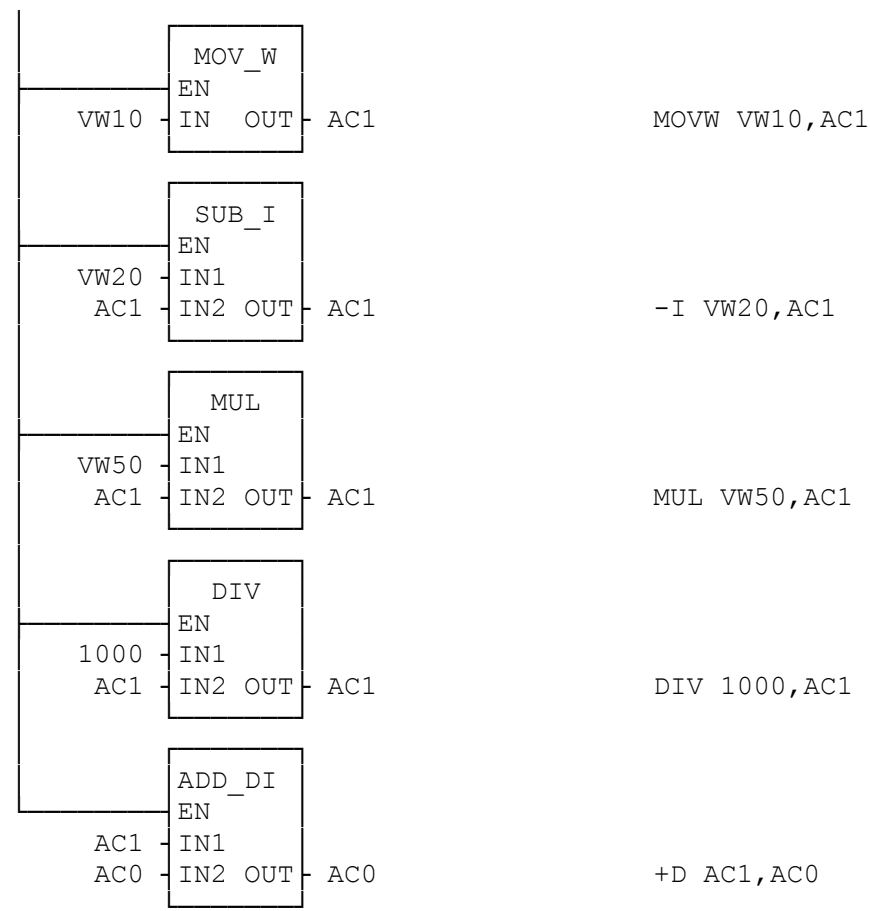

PID control action output:

The discrete representation of the PID control loop is given by the equation: $G(t)=K p E(k T)+\frac{k i T}{2} \sum_{k=0}^{n}[E(k T)+E((k+1) T)]+\frac{K d}{T}[E((k+1) T)-E(k T)]$

This equation consists of three parts implemented as follows :

I- Proportional part $G p(t)=K p E(k T)$

- Put previous error in accumulator (AC0)

- Multiply it by Kp

- Store the result in (AC0)

II- Integral part $G_{i}(t)=\frac{k i T}{2} \sum_{k=0}^{n}[E(k T)+E((k+1) T)]$

- $\quad$ Put previous error in accumulator (AC1)

- $\quad$ Add recent error to (AC1)

- $\quad$ Multiply result by $\mathrm{Ki}$ and accumulate in (AC1)

- $\quad$ Multiply the value of $(\mathrm{AC} 1)$ by the time period $\mathrm{T}$ and store the value in (AC1)

- $\quad$ Add the integral part to the overall output in (AC0)

III- Differential part $G_{d}(t)=\frac{K d}{T}[E((k+1) T)-E(k T)]$

- $\quad$ Put recent error in accumulator (AC1)

- $\quad$ Subtract previous error from (AC1) and store result in (AC1)

- $\quad$ Multiply the result by $\mathrm{Kd}$ and accumulate in (AC1)

- $\quad$ Divide output by T

- $\quad$ Add the differential action output to the overall output stored in (AC0)

Network 7

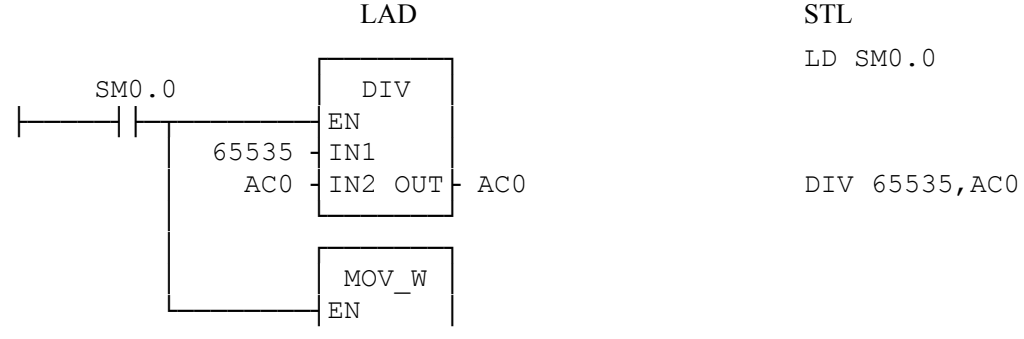


Am. J. Applied Sci., 4 (5): 307-316, 2007

$$
\text { ACO -IN OUT VW100 MOVW AC0, VW100 }
$$

Scaling :

This network is necessary for scaling the output to comply with the next steps and give a flexible range of variation for the controller constants. 65535 is the maximum possible 16-bit (word) value.

Network 8

LAD

(END)
STL

MEND

Main program END:

This network flags the end of the main program, Subroutines and interrupts are not parts of the main program; they are written afterwards as stand-alone units.

Network 9



This subrOutine

This subroutine is executed once at the first scan, its purpose is to initialize the function of the PWM featured by CPU-214 as follows. Network 10

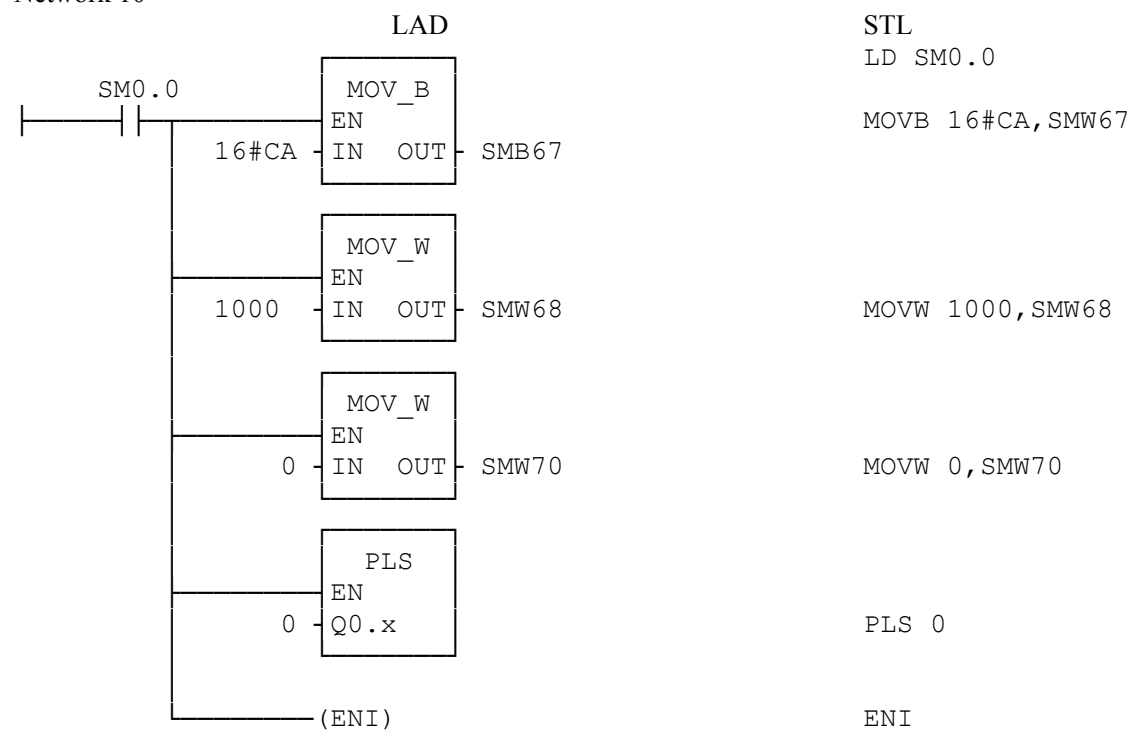

Control byte for PWM is stored in special memory byte (SM67) as illustrated in the following Table: Table (2.1.1): PWM Control Byte

\begin{tabular}{|c|c|c|c|c|c|c|c|c|}
\hline \multicolumn{9}{|c|}{ SM67.x } \\
\hline Bit no. & 7 & 6 & 5 & 4 & 3 & 2 & 1 & 0 \\
\hline Bit value & 1 & 1 & 0 & 0 & 1 & 0 & 1 & 0 \\
\hline effect & $\begin{array}{c}\text { Enable } \\
\text { PWM }\end{array}$ & $\begin{array}{l}\text { Select } \\
\text { PWM }\end{array}$ & & & $\begin{array}{l}\text { (msec/tick) } \\
\text { increments }\end{array}$ & $\begin{array}{l}\text { No update } \\
\text { for pulse } \\
\text { count }\end{array}$ & $\begin{array}{l}\text { Update pulse } \\
\text { width time } \\
\text { value }\end{array}$ & $\begin{array}{l}\text { No update } \\
\text { for cycle } \\
\text { time }\end{array}$ \\
\hline
\end{tabular}

- $\quad$ The hexadecimal equivalent for (2 \# 11001010$)$ is (16 \# CA)

- $\quad$ Cycle time is stored in the special memory word (SM68)

- $\quad$ Pulse width is initialized to be (zero) and stored in the special memory word (SM70)

- $\quad$ Invoke PWM operation (PLS $0 \rightarrow$ activate Q 0.0)

- Enable all interrupts (ENI)

Network 11

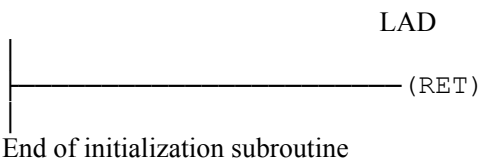

STL

RET

End of initialization subroutine

Network 12 
Am. J. Applied Sci., 4 (5): 307-316, 2007

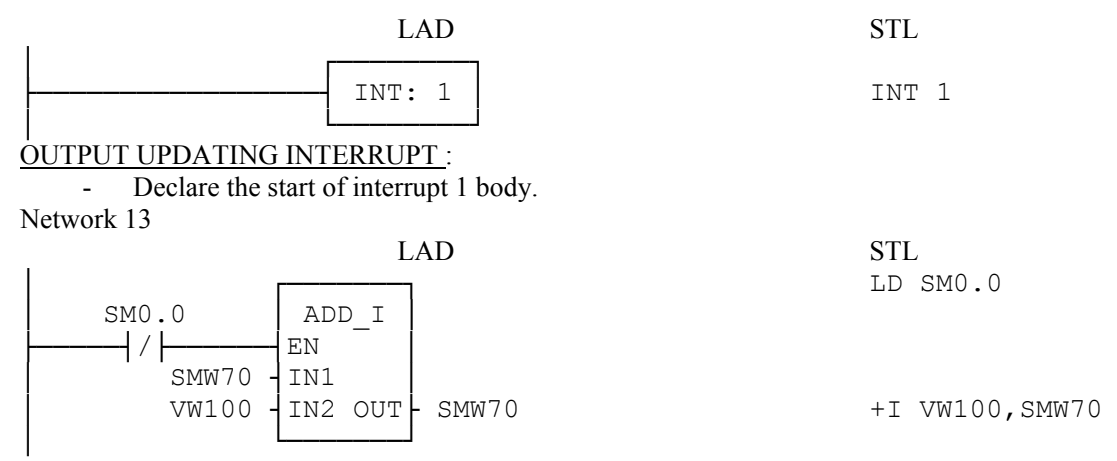

Each time (I0.0) transitions from OFF to ON, increase/decrease the pulse width depending on the sign and magnitude of controllers output stored in (VW100)

Network 14

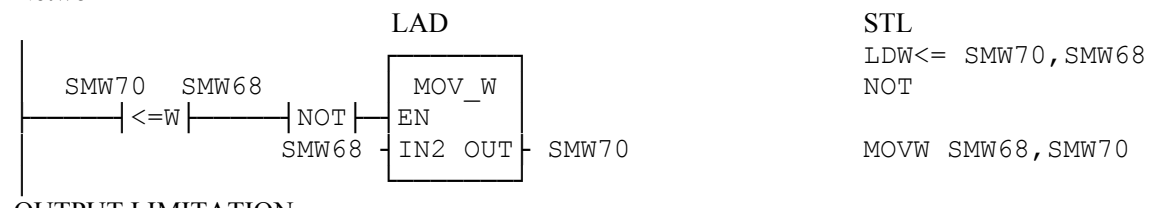

OUTPUT LIMITATION:

If the pulse width (SM70) exceeds the duty cycle (due to controller output) ignore the excessive increment and store the maximum applicable pulse width, which is equal to the cycle time (SM68).

Network 15

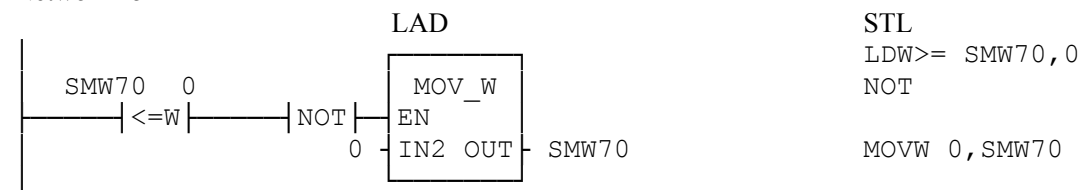

this network prevents negative values of pulse width and stores a (zero) in (SM70) if such values occur.

Network 16

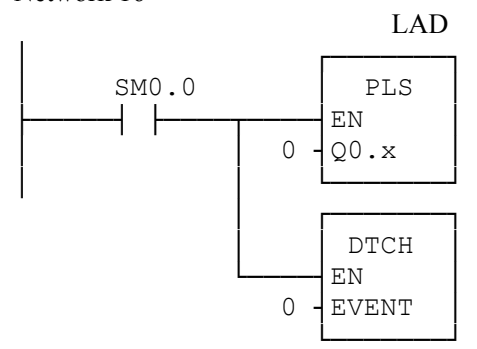

STL

LD SMO. 0

PLS 0

$\mathrm{DTCH} \quad \mathrm{O}$

- $\quad$ Update the pulse width Network 17

De-attach the event 0 to disable rising edge interrupt.

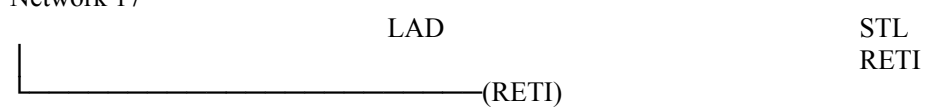

End of interrupt 1

End of PLC program

instructions for logic operations, math operations, data moves and program control functions as calls, interrupts, subroutines and so on. Some functions are of the PLC's advanced features such as the instant PWM, which depends on special memory bytes (SM67, SM68). So, a ready function of PWM is utilized in order to reduce the size of the program, assuming that programming of this function from scratch is straight forward,${ }^{[3]}$. The block diagram of the control system is shown in Fig. 2.

The instantaneous temperature value is conveyed by eight parallel lines connected to eight input points of the PLC as given in Table 1.

The desired output of the control loop is a digital level passed to one output point of the PLC, (Q 0.0). Due to programming demands in order to avoid 
Am. J. Applied Sci., 4 (5): 307-316, 2007

\begin{tabular}{|c|c|c|c|c|c|c|c|c|c|c|c|}
\hline $\begin{array}{l}\text { Time } \\
{[\mathrm{sec}]}\end{array}$ & $\begin{array}{c}\text { Temp. } \\
\text { [C] }\end{array}$ & $\begin{array}{l}\text { Time } \\
{[\mathrm{sec}]}\end{array}$ & $\begin{array}{c}\text { Temp. } \\
\text { [C] }\end{array}$ & $\begin{array}{l}\text { Time } \\
{[\mathrm{sec}]}\end{array}$ & $\begin{array}{c}\text { Temp. } \\
\text { [C] }\end{array}$ & $\begin{array}{l}\text { Time } \\
{[\mathrm{sec}]}\end{array}$ & $\begin{array}{c}\text { Temp. } \\
\text { [C] }\end{array}$ & $\begin{array}{l}\text { Time } \\
{[\mathrm{sec}]}\end{array}$ & $\begin{array}{c}\text { Temp. } \\
\text { [C] }\end{array}$ & $\begin{array}{l}\text { Time } \\
{[\mathrm{sec}]}\end{array}$ & $\begin{array}{c}\text { Temp. } \\
\text { [C] }\end{array}$ \\
\hline 10 & 29.3 & 410 & 47.3 & 810 & 46.7 & 1210 & 46.4 & 1610 & 46.2 & 2010 & 45.5 \\
\hline 20 & 29.8 & 420 & 46.9 & 820 & 46.8 & 1220 & 46.4 & 1620 & 46.2 & 2020 & 45.4 \\
\hline 30 & 31.9 & 430 & 46.5 & 830 & 46.8 & 1230 & 46.4 & 1630 & 46.2 & 2030 & 45.3 \\
\hline 40 & 32.2 & 440 & 46.0 & 840 & 46.8 & 1240 & 46.4 & 1640 & 46.2 & 2040 & 45.2 \\
\hline 50 & 33.0 & 450 & 45.5 & 850 & 46.8 & 1250 & 46.3 & 1650 & 41.8 & 2050 & 45.1 \\
\hline 60 & 33.8 & 460 & 45.2 & 860 & 46.7 & 1260 & 46.3 & 1660 & 42.5 & 2060 & 44.9 \\
\hline 70 & 34.6 & 470 & 44.2 & 870 & 46.6 & 1270 & 46.3 & 1670 & 43.6 & 2070 & 43.7 \\
\hline 80 & 35.3 & 480 & 44.1 & 880 & 46.5 & 1280 & 46.3 & 1680 & 44.0 & 2080 & 43.8 \\
\hline 90 & 36.4 & 490 & 44.1 & 890 & 46.4 & 1290 & 46.3 & 1690 & 44.5 & 2090 & 45.0 \\
\hline 100 & 37.6 & 500 & 44.0 & 900 & 46.3 & 1300 & 46.3 & 1700 & 46.1 & 2100 & 45.3 \\
\hline 110 & 38.7 & 510 & 44.6 & 910 & 45.8 & 1310 & 46.2 & 1710 & 46.9 & 2110 & 45.3 \\
\hline 120 & 39.7 & 520 & 45.8 & 920 & 46.5 & 1320 & 46.1 & 1720 & 47.9 & 2120 & 45.1 \\
\hline 130 & 40.8 & 530 & 46.4 & 930 & 45.5 & 1330 & 45.9 & 1730 & 48.3 & 2130 & 44.8 \\
\hline 140 & 42.1 & 540 & 46.7 & 940 & 45.4 & 1340 & 45.6 & 1740 & 48.7 & 2140 & 44.6 \\
\hline 150 & 43.3 & 550 & 46.9 & 950 & 45.3 & 1350 & 45.7 & 1750 & 49.3 & 2150 & 44.6 \\
\hline 160 & 44.4 & 560 & 47.1 & 960 & 45.2 & 1360 & 45.9 & 1760 & 49.7 & 2160 & 44.6 \\
\hline 170 & 45.6 & 570 & 47.2 & 970 & 45.4 & 1370 & 46.2 & 1770 & 49.9 & 2170 & 44.5 \\
\hline 180 & 47.6 & 580 & 47.3 & 980 & 45.7 & 1380 & 46.2 & 1780 & 50.1 & 2180 & 44.5 \\
\hline 190 & 48.4 & 590 & 47.3 & 990 & 46.3 & 1390 & 46.2 & 1790 & 50.2 & 2190 & 44.3 \\
\hline 200 & 49.4 & 600 & 47.2 & 1000 & 46.5 & 1400 & 46.2 & 1800 & 50.2 & 2200 & 44.0 \\
\hline 210 & 50.1 & 610 & 47.2 & 1010 & 46.6 & 1410 & 46.2 & 1810 & 50.2 & 2210 & 44.0 \\
\hline 220 & 50.6 & 620 & 47.1 & 1020 & 46.6 & 1420 & 46.2 & 1820 & 50.1 & 2220 & 44.1 \\
\hline 230 & 50.9 & 630 & 47.1 & 1030 & 46.6 & 1430 & 46.2 & 1830 & 50.0 & 2230 & 44.0 \\
\hline 240 & 51.3 & 640 & 46.9 & 1040 & 46.5 & 1440 & 46.2 & 1840 & 49.9 & 2240 & 44.0 \\
\hline 250 & 51.4 & 650 & 46.8 & 1050 & 46.6 & 1450 & 46.2 & 1850 & 49.8 & 2250 & 43.8 \\
\hline 260 & 51.4 & 660 & 46.6 & 1060 & 46.4 & 1460 & 46.2 & 1860 & 49.7 & 2260 & 43.8 \\
\hline 270 & 51.3 & 670 & 46.5 & 1070 & 46.3 & 1470 & 46.2 & 1870 & 49.5 & 2270 & 43.7 \\
\hline 280 & 51.3 & 680 & 46.2 & 1080 & 46.1 & 1480 & 46.2 & 1880 & 49.2 & 2280 & 43.7 \\
\hline 290 & 51.1 & 690 & 45.5 & 1090 & 45.8 & 1490 & 46.2 & 1890 & 49.0 & 2290 & 43.5 \\
\hline 300 & 50.9 & 700 & 45.5 & 1100 & 45.6 & 1500 & 46.2 & 1900 & 48.8 & 2300 & 43.6 \\
\hline 310 & 50.6 & 710 & 45.2 & 1110 & 45.4 & 1510 & 46.2 & 1910 & 48.6 & 2310 & 43.6 \\
\hline 320 & 50.3 & 720 & 44.4 & 1120 & 45.3 & 1520 & 46.2 & 1920 & 48.5 & 2320 & 43.4 \\
\hline 330 & 50.0 & 730 & 44.5 & 1130 & 45.4 & 1530 & 46.2 & 1930 & 48.2 & 2330 & 43.2 \\
\hline 340 & 49.7 & 740 & 44.3 & 1140 & 45.6 & 1540 & 46.2 & 1940 & 48.0 & 2340 & 43.2 \\
\hline 350 & 49.4 & 750 & 44.9 & 1150 & 46.2 & 1550 & 46.2 & 1950 & 47.7 & 2350 & 43.2 \\
\hline 360 & 49.1 & 760 & 45.6 & 1160 & 46.3 & 1560 & 46.2 & 1960 & 47.6 & 2360 & 43.2 \\
\hline 370 & 48.6 & 770 & 45.7 & 1170 & 46.3 & 1570 & 46.2 & 1970 & 47.4 & 2370 & 43.2 \\
\hline 380 & 48.3 & 780 & 46.3 & 1180 & 46.4 & 1580 & 46.2 & 1980 & 46.3 & 2380 & 43.2 \\
\hline 390 & 48.0 & 790 & 46.5 & 1190 & 46.4 & 1590 & 46.2 & 1990 & 45.5 & 2390 & 43.2 \\
\hline 400 & 47.6 & 800 & 46.6 & 1200 & 46.4 & 1600 & 46.2 & 2000 & 45.6 & 2936 & 43.2 \\
\hline
\end{tabular}

Table 4: Temperature readings for PI mode with disturbance

\begin{tabular}{|c|c|c|c|c|c|c|c|c|c|c|c|}
\hline $\begin{array}{l}\text { Time } \\
{[\mathrm{sec}]}\end{array}$ & Temp. [C] & $\begin{array}{l}\text { Time } \\
{[\mathrm{sec}]}\end{array}$ & $\begin{array}{l}\text { Temp } \\
{[\mathrm{C}]}\end{array}$ & $\begin{array}{l}\text { Time } \\
{[\mathrm{sec}]}\end{array}$ & Temp. [C] & $\begin{array}{l}\text { Time } \\
{[\mathrm{sec}]}\end{array}$ & Temp. [C] & $\begin{array}{l}\text { Time } \\
{[\mathrm{sec}]}\end{array}$ & Temp. [C] & $\begin{array}{l}\text { Time } \\
{[\mathrm{sec}]}\end{array}$ & Temp. [C] \\
\hline 10 & 24.0 & 410 & 50.0 & 810 & 54.7 & 1210 & 53.3 & 1610 & 44.5 & 2010 & 52.3 \\
\hline 20 & 26.0 & 420 & 50.0 & 820 & 54.8 & 1220 & 53.3 & 1620 & 44.7 & 2020 & 52.0 \\
\hline 30 & 27.5 & 430 & 49.9 & 830 & 54.9 & 1230 & 53.3 & 1630 & 44.7 & 2030 & 51.8 \\
\hline 40 & 30.4 & 440 & 49.8 & 840 & 54.8 & 1240 & 53.3 & 1640 & 45.6 & 2040 & 51.6 \\
\hline 50 & 32.6 & 450 & 49.6 & 850 & 54.9 & 1250 & 53.3 & 1650 & 46.4 & 2050 & 51.4 \\
\hline 60 & 35.2 & 460 & 49.8 & 860 & 55.0 & 1260 & 53.3 & 1660 & 46.7 & 2060 & 51.2 \\
\hline 70 & 37.0 & 470 & 49.7 & 870 & 54.9 & 1270 & 53.3 & 1670 & 47.6 & 2070 & 51.3 \\
\hline 80 & 38.4 & 480 & 49.8 & 880 & 54.9 & 1280 & 53.3 & 1680 & 48.2 & 2080 & 51.2 \\
\hline 90 & 40.7 & 490 & 49.9 & 890 & 54.8 & 1290 & 53.3 & 1690 & 48.8 & 2090 & 51.3 \\
\hline 100 & 41.7 & 500 & 50.0 & 900 & 54.8 & 1300 & 53.3 & 1700 & 49.0 & 2100 & 51.3 \\
\hline 110 & 42.6 & 510 & 50.1 & 910 & 54.7 & 1310 & 53.3 & 1710 & 49.2 & 2110 & 51.4 \\
\hline 120 & 43.6 & 520 & 50.2 & 920 & 54.5 & 1320 & 53.3 & 1720 & 50.0 & 2120 & 51.5 \\
\hline 130 & 44.8 & 530 & 50.3 & 930 & 54.0 & 1330 & 53.3 & 1730 & 50.2 & 2130 & 51.6 \\
\hline 140 & 45.9 & 540 & 50.4 & 940 & 53.9 & 1340 & 53.3 & 1740 & 50.6 & 2140 & 51.7 \\
\hline 150 & 47.2 & 550 & 50.6 & 950 & 53.3 & 1350 & 53.3 & 1750 & 51.0 & 2150 & 51.9 \\
\hline 160 & 48.5 & 560 & 50.9 & 960 & 53.2 & 1360 & 53.3 & 1760 & 51.2 & 2160 & 52.0 \\
\hline 170 & 49.7 & 570 & 50.9 & 970 & 53.0 & 1370 & 53.3 & 1770 & 51.5 & 2170 & 52.1 \\
\hline 180 & 50.8 & 580 & 51.0 & 980 & 52.8 & 1380 & 53.3 & 1780 & 52.0 & 2180 & 52.3 \\
\hline
\end{tabular}


Am. J. Applied Sci., 4 (5): 307-316, 2007

\begin{tabular}{|c|c|c|c|c|c|c|c|c|c|c|c|}
\hline 190 & 51.8 & 590 & 51.1 & 990 & 52.6 & 1390 & 53.3 & 1790 & 51.9 & 2190 & 52.4 \\
\hline 200 & 52.7 & 600 & 51.3 & 1000 & 52.5 & 1400 & 53.3 & 1800 & 52.5 & 2200 & 52.6 \\
\hline 210 & 53.4 & 610 & 51.2 & 1010 & 52.4 & 1410 & 53.3 & 1810 & 53.4 & 2210 & 52.7 \\
\hline 220 & 54.0 & 620 & 51.4 & 1020 & 52.4 & 1420 & 53.3 & 1820 & 54.5 & 2220 & 52.7 \\
\hline 230 & 54.3 & 630 & 51.3 & 1030 & 52.5 & 1430 & 53.3 & 1830 & 55.0 & 2230 & 52.7 \\
\hline 240 & 54.6 & 640 & 51.4 & 1040 & 52.5 & 1440 & 53.3 & 1840 & 56.0 & 2240 & 52.7 \\
\hline 250 & 54.7 & 650 & 51.3 & 1050 & 52.7 & 1450 & 53.3 & 1850 & 56.7 & 2250 & 52.6 \\
\hline 260 & 54.6 & 660 & 51.3 & 1060 & 53.0 & 1460 & 53.3 & 1860 & 58.0 & 2260 & 52.7 \\
\hline 270 & 54.6 & 670 & 50.5 & 1070 & 53.1 & 1470 & 53.3 & 1870 & 58.3 & 2270 & 52.6 \\
\hline 280 & 54.4 & 680 & 50.7 & 1080 & 53.2 & 1480 & 53.3 & 1880 & 58.3 & 2280 & 52.5 \\
\hline 290 & 54.1 & 690 & 50.8 & 1090 & 53.1 & 1490 & 53.3 & 1890 & 58.0 & 2290 & 52.7 \\
\hline 300 & 53.8 & 700 & 50.8 & 1100 & 53.4 & 1500 & 53.3 & 1900 & 57.5 & 2300 & 52.8 \\
\hline 310 & 53.4 & 710 & 51.0 & 1110 & 53.5 & 1510 & 53.3 & 1910 & 57.1 & 2310 & 52.9 \\
\hline 320 & 53.1 & 720 & 51.2 & 1120 & 53.6 & 1520 & 53.3 & 1920 & 56.7 & 2320 & 52.9 \\
\hline 330 & 52.7 & 730 & 51.4 & 1130 & 53.6 & 1530 & 53.3 & 1930 & 56.1 & 2330 & 53.0 \\
\hline 340 & 52.3 & 740 & 51.6 & 1140 & 53.7 & 1540 & 53.3 & 1940 & 55.6 & 2340 & 53.1 \\
\hline 350 & 51.8 & 750 & 52.2 & 1150 & 53.7 & 1550 & 53.3 & 1950 & 55.0 & 2350 & 53.2 \\
\hline 360 & 51.4 & 760 & 52.5 & 1160 & 53.5 & 1560 & 53.3 & 1960 & 54.5 & 2360 & 53.2 \\
\hline 370 & 51.1 & 770 & 52.8 & 1170 & 53.5 & 1570 & 53.3 & 1970 & 53.4 & 2370 & 53.3 \\
\hline 380 & 50.8 & 780 & 53.4 & 1180 & 53.5 & 1580 & 53.3 & 1980 & 53.1 & 2380 & 53.3 \\
\hline 390 & 50.5 & 790 & 53.9 & 1190 & 53.4 & 1590 & 53.3 & 1990 & 52.1 & 2390 & 53.3 \\
\hline 400 & 50.2 & 800 & 54.7 & 1200 & 53.4 & 1600 & 53.3 & 2000 & 52.4 & 2936 & 53.3 \\
\hline
\end{tabular}

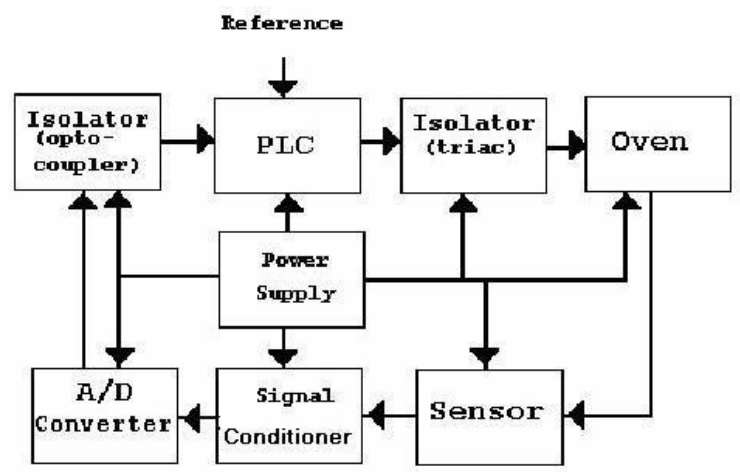

Fig. 2: Control block diagram

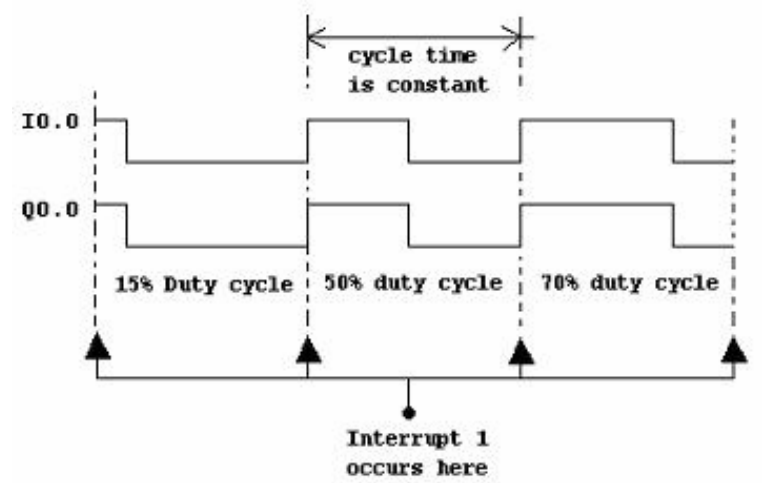

Fig. 3: PWM output timing diagram

undesirable jitter in the controlled variable synchronous updates to the pulse width are realized by feeding back the pulse output to the interrupt input point. By enabling (attaching the event) the rising edge interrupt of the input (I 0.0), PWM cycle is synchronized ${ }^{[4]}$, as illustrated in Fig. 3.

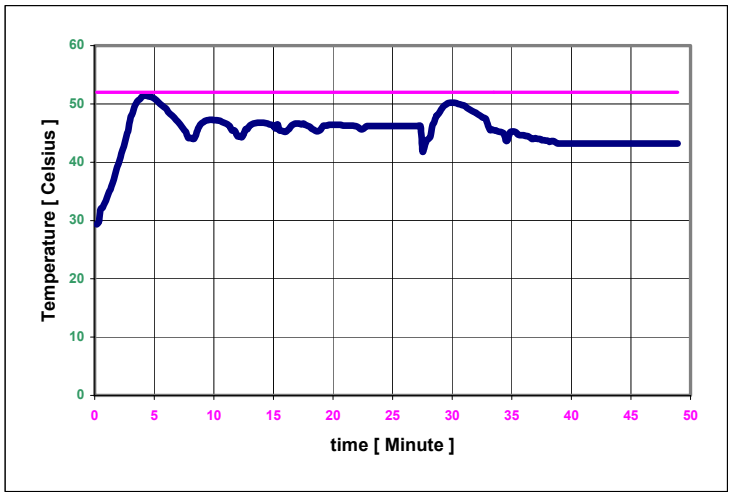

Fig. 4: Practical output characteristic of proportional action with $20 \%$ gain

PLC program: The Table 2 contains the PLC program written in ladder diagram and statement list forms and illustrated network by network. Important to note that interrupts and subroutines are not parts of the main program body. They function as independent units when called.

\section{EXPERIMENTAL RESULTS}

The control system has been tested with different controller settings of the PID actions. Experiment took place in the process control laboratory by using the heater of the training board (RGTI),${ }^{[5]}$. The initial temperature of the heater was equal to room temperature. Figure 4 and Table 3 show the time characteristic of the controlled variable when the controller was in the proportional mode. After temperature has settled in a steady state mode, at the 


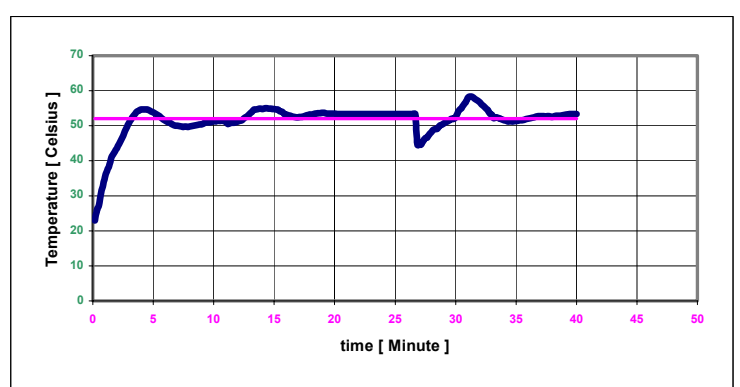

Fig. 5: Practical output characteristic of proportional integral action

$27^{\text {th }}$ minute the heater was subjected to an external disturbance for an instant. The figure shows the reaction of the controller and how the variable settled again into a new steady state. The response was obtained with a $20 \%$ gain. Consequently the offset is considerably high. When the gain was increased to $60 \%$, a noticeable overshoot occurred and the offset decreased. Note that the curve is not perfectly smooth this is due to external disturbances such as the opening and closure of the doors of the laboratory and the AC unit, which has also participated, in some noisy values included in the reading. Another factor is the small heat capacity of the heater.

Figure 5 and Table 4 show system response in the PI mode. The load was disturbed at the $27^{\text {th }}$ minute and the controller cleared the error and retrieved the previous steady state.

\section{CONCLUSION}

* Using PLC a custom design of a software PID/PWM control algorithm was carried out and implemented to control a heater temperature in a closed-loop system. At the same time a PLC analogue input binary output interface board was specifically designed to be compatible with the software program.
* Power interface between the controller output and the load was realized by transforming the PID digital output into a PWM signal in order to trigger the power switch. This helped reducing the error due D/A conversion, maximized utilization of the PLC and reduced the total cost.

* The programmed software could be used with other PLCs which do not support PID kit or PLC analogue input binary output interface board.

\section{REFERENCES}

1. Webb, J.W. and R.A. Reis, 1995. Programmable Logic Controllers. Principles and Applications, Prentice Hall, Ohio. U.S.A

2. Johnson, G.W., 1994. LabVIEW Graphical Programming, Practical Applications in Instrumentation and Control. Mc. Graw-hill, INC, U.S.A.

3. Alia, M.A.K., 2002. Realizing Programmable PWM By Using PLCs. Helwan University, Faculty of Engineering, Engineering Research Journal, Vol. 82, Egypt.

4 Siemens, Simatic S7, Step 7-microprogramming. 6ES7 022-1 AX00-8BH0, Release 02, 1995, Germany.

5. Dellrenzo, Viale Romagna, 20-20089 Rozzono, Electronic laboratory board for study of temperature control, Milano-Italy. 